\title{
Effects of season and breed on the reproductive performance of sheep
}

\author{
Hany A. Zaher ${ }^{1,2, *}$, Saeed A. Alawaash ${ }^{1}$ and Ayman A. Swelum ${ }^{2,3, *}$ \\ ${ }^{1}$ Research and Development Division, Abu Dhabi Agriculture and Food Safety Authority, Abu Dhabi 52150, United Arab \\ Emirate \\ ${ }^{2}$ Department of Theriogenology, Faculty of Veterinary Medicine, Zagazig University, Sharkia 44519, Egypt \\ ${ }^{3}$ Department of Animal Production, College of Food and Agriculture Sciences, King Saud University, Riyadh 11451, \\ Saudi Arabia
}

Received May 5, 2020

Revised May 28, 2020

Accepted June 1, 2020

*Correspondence
Hany A. Zaher
E-mail: hany.mohamed@adafsa.gov.ae
ORCID
https://orcid.org/0000-0003-1834-2589
Ayman A. Swelum
E-mail: aymanswelum@zu.edu.eg
ORCID
https://orcid.org/0000-0003-3247-5898

https://orcid.org/0000-0003-3247-5898

\begin{abstract}
The aim of the current study was to compare the effects of season and breed on the reproductive performance of male and female sheep using 12 rams and 318 ewes of Assaf and Awassi breeds under the seasonal environmental condition of United Arab Emirates for two years. The blood level of testosterone hormone was measured monthly. Semen was collected twice a month from each male using artificial vagina and evaluated for volume, motility, livability, abnormality and concentration. The scrotal circumference and thickness as well as the left testicular length, width, height and volume were measured at one-month intervals. The level of testosterone in Assaf breed was significantly higher in autumn than winter and summer. The scrotal circumference and thickness as well as the left testicular length were significantly higher in Assaf breed than Awassi breed. While, left testicular width and volume were significantly higher in Awassi breed than Assaf breed. Scrotal circumference which was higher in spring and summer than in autumn and winter season in both breeds. The SCC of semen was significantly higher in autumn than in other seasons in both breeds. The sperm abnormality was significantly higher in summer than other seasons in both breeds. The livability was significantly lower in summer in both breeds. Fecundity and prolificacy were significantly higher in Assaf than Awassi breed during autumn season. Assaf breed showed the superior reproductive performance in the autumn season when compared with Awassi breed in the same season and other seasons. The Assaf breed tolerated the climatic conditions in UAE and kept the litter size of 1.72 in comparison to Awassi breed which showed litter size of 1.09. in conclusion, the results showed the superiority of Assaf over Awassi breed and offer a good model of breeding with increased fecundity and prolificacy specially in autumn season.
\end{abstract}

Keywords: Assaf, Awassi, breed, fertility, seasonal variations, sheep, sperm

\section{INTRODUCTION}

The ram is the most important member of the flock, yet often the most neglected. Ram contributes half of the genetics to the flock and his success as a breeder will go a long way towards ensuring a profitable lamb crop. Different farms maintain different breeds of sheep and goat breeds in UAE as per the choice of the owner. Food and 
Agriculture Organization (FAO) stated in one of its reports (FAO, 1991) that the genetic potential and productivity of goats and sheep are deteriorating due to indiscriminate type of breeding. This may be minimized by providing sound breeding knowledge to the breeders including the most adapted breed for the Environmental conditions and the breeding seasonality. In the UAE, the climate condition is very adverse during summer months, which can affect semen quality. It is well known that the sexual behavior, semen quality and quantity are the main factors that limit male reproductive efficiency during the year. These factors could vary according to different environmental and physiological factors such as climate (Zarei et al., 2009); latitude, breeding season of the year (Karagiannidis et al., 2000). Semen quality can be affected by breed, age, nutritional factors, environmental factors like ambient temperature, humidity, hours of day light etc. (Al Samarrae, 2009; Moghaddam et al., 2012; Malejane et al., 2014). Multiple ovulations and embryo transfer results are significantly affected by the breed (Swelum et al., 2014). Additionally, the ovarian activity are significantly affected by season (Yu et al., 2017). Selection of young rams for fertility can be accomplished through selecting some important reproductive traits such as age at puberty, body condition score, body growth rate, scrotal circumference, scrotal growth rate And semen quality (Land and Carr, 1975). Various factors affecting ejaculate volume and semen quality have been reported in literature. These include breed, season of the year, age of the male, nutritional status of the animal, reproductive management, skill of the semen collector, responsiveness of the ram, method and the frequency of semen collection (Talebi et al., 2009). Humidity and temperature changes can cause thermal discomfort, resulting in a decrease in food intake and interference with spermatogenesis and semen quality (Kunavongkrit et al., 2005). Level of sexual hormones, affected by climate changes, has a great influence on the physiological chain of events involved in the sexual cycle (Abecia et al., 2012). Testosterone is the hormone responsible for spermatogenesis and sexual behavior, thus the seasonal pattern of testosterone secretion could limit the male reproductive efficiency during some periods of the year (Todini et al., 2007). Testosterone level is correlated positively and significantly with sperm motility and progressive motility (Swelum et al., 2017). It is hypothesized that season and breed can affect the reproductive perfor- mance sheep. Therefore, the current study aimed to compare the effects of season and breed (Assaf and Awassi) on the reproductive performance of male and female sheep under the condition of United Arab Emirates.

\section{MATERIALS AND METHODS}

The current research was conducted at Baniyas Research Station, Research and Development Division, Development Sector, Abu Dhabi Agriculture and Food Safety Authority, Abu Dhabi, United Arab Emirates for two years. Average daily temperature $\left({ }^{\circ} \mathrm{C}\right)$, humidity $\%$ and average sun hours/day in Abu Dhabi are illustrated in Table 1. The experimental protocol regarding the care and handling of animals had been approved by the Ethics Committee of the Research and Development Division, Development Sector, Abu Dhabi Agriculture and Food Safety Authority.

Two sheep breeds (Assaf and Awassi) were included in this study. Animals are maintained under similar feeding and management conditions. Males are kept separated from females in different sheds. Six healthy males from each breed aged 3-5 years were selected for semen evaluation. Within each breed, males of almost the same body weight and body condition score were selected. Males were trained for semen collection using artificial vagina, while ewes in estrus were used as mounts. Blood samples were collected monthly for two years from animals of the different sheep breeds and sent to laboratory to estimate the level of testosterone hormone. Semen was collected twice a month from each male for two years using artificial vagina. Collected semen samples were identified and immediately transferred to the lab to be tested. Macroscopic characteristic of semen (volume) was recorded. Fresh semen samples were used to study the microscopic characteristics of semen. These included, sperm motility (progressive forward motility), live and dead sperms percentage (livability) using eosin nigrosine stain, sperm

Table 1. Average daily temperature $\left({ }^{\circ} \mathrm{C}\right)$, humidity $\%$ and average sun hours/month in Abu Dhabi

\begin{tabular}{lrrrr}
\hline \multicolumn{1}{c}{ Season (months) } & $\begin{array}{c}\text { Autumn } \\
\text { (Sep-Nov) }\end{array}$ & $\begin{array}{c}\text { Winter } \\
\text { (Dec-Feb) }\end{array}$ & $\begin{array}{c}\text { Spring } \\
\text { (Mar-May) }\end{array}$ & $\begin{array}{c}\text { Summer } \\
\text { (Jun-Aug) }\end{array}$ \\
\hline Average daily tempera- & $34.4 \pm 2.5$ & $24.1 \pm 1.2$ & $30.8 \pm 2.1$ & $40.5 \pm 3.1$ \\
ture ${ }^{\circ} \mathrm{C}$ & & & & \\
Humidity \% & $64.2 \pm 3.7$ & $69.2 \pm 4.1$ & $48.1 \pm 2.9$ & $50.3 \pm 4.1$ \\
Average sun hours/day & $9.6 \pm 1.1$ & $8.0 \pm 0.4$ & $10.4 \pm 1.2$ & $10.9 \pm 1.3$ \\
\hline
\end{tabular}


abnormality using alkaline methyl violet and sperm concentration using hemocytometer method. The scrotal circumference and thickness as well as the left testicular length, width and height were measured at its maximum dimension in sitting position at one-month intervals for two years using a coulter scrotal tape and caliper. Left testicular volume was calculated using following formula (volume $=$ length $\times$ width $\times$ height $\times 0.71$ ).

Three-hundred-eighteen ewes of two sheep breeds (Assaf $[n=168]$ and Awassi $[n=150]$ ) aged 2-3 years were selected for fertility trial during two years. Estrus synchronization was carried out with the aid of intra-vaginal polyurethane sponges impregnated with $30 \mathrm{mg}$ fluorogestone acetate (FGA; Synchropart ${ }^{\circledR}$, Ceva Sante, Animale, France). Intra-vaginal sponge was left in the vagina for a 14-day period (Swelum et al., 2015). Rams were joined to ewes in a rate of 1:4 and left together for three weeks. Pregnancy was diagnosed ultrasonography using multifrequency convex abdominal probe (Model UST-9137C, Aloka, Japan). Number of fetuses were recorded and confirmed at lambing. Pregnancy rate (pregnant ewes detected by ultrasound/matted ewes*100), lambing rate (lambed ewes/inseminated ewes*100), twining rate (ewes lambed twins/pregnant ewes*100), abortion rate (aborted ewes/ pregnant ewes*100) fecundity (newborn lambs/inseminated ewes) and prolificacy or litter size (newborn lambs/ pregnant ewes) were calculated (Swelum et al., 2018a; Swelum et al., 2018b).

Comparisons among groups were analyzed by repeated measures analysis of variance (ANOVA), using SAS (SAS
Institute, Cary, NC, USA, 2000) to evaluate the effect of breed and season. Data were expressed as the mean \pm standard error. Fertility parameters were evaluated using Chi Square $\left(\chi^{2}\right)$ test and expressed as percentages. A difference was considered significant at $p<0.05$ level.

\section{RESULTS}

Effects of season and breed of sheep on testosterone levels are effect presented in Table 2. Regarding the season effect within the same breed, there is no significant effect for season on testosterone level in Awassi breed. While, the level of testosterone in Assaf breed was significantly higher in autumn than winter and summer. Regarding the breed effect within the same season, the level of testosterone was insignificantly differed between Assaf and Awassi breeds during all seasons.

The effects of season and breed of sheep on testicular and scrotal morphometric parameters are presented in

Table 2. Effects of season and breed of sheep on testosterone levels

\begin{tabular}{lcccc}
\hline Breed & Autumn & Winter & Spring & Summer \\
\hline Assaf & $720.83 \pm 132.23^{\mathrm{a}}$ & $401.92 \pm 67.81^{\mathrm{b}}$ & $466.92 \pm 97.67^{\mathrm{a}, \mathrm{b}}$ & $397.25 \pm 84.77^{\mathrm{b}}$ \\
Awassi & $697.42 \pm 136.38$ & $455.08 \pm 45.67$ & $547.73 \pm 143.74$ & $679.75 \pm 127.06$
\end{tabular}

Means \pm standard error carrying different capital letters (A, B) within the same column and parameter are significantly differed $(p \leq 0.05)$ (Effect of breed).

Means \pm standard error carrying different superscript ( $a, b, c$, and $d)$ within the same row and parameter significantly differed $(p \leq 0.05)$ (Effect of season).

Table 3. Effects of season and breed of sheep on testicular and scrotal morphometric parameters

\begin{tabular}{|c|c|c|c|c|c|}
\hline Parameter & & Autumn & Winter & Spring & Summer \\
\hline \multirow[t]{2}{*}{ Testicular length } & Assaf & $13.45 \pm 1.08^{\mathrm{A}}$ & $13.45 \pm 1.10^{A}$ & $13.47 \pm 1.07^{\mathrm{A}}$ & $13.50 \pm 1.13^{\mathrm{A}}$ \\
\hline & Awassi & $13.00 \pm 0.76^{B}$ & $12.87 \pm 0.73^{B}$ & $12.90 \pm 0.70^{B}$ & $12.95 \pm 0.65^{B}$ \\
\hline Testicular width & Awassi & $8.32 \pm 0.94^{A}$ & $8.32 \pm 0.96^{A}$ & $8.37 \pm 0.95^{A}$ & $8.38 \pm 0.94^{A}$ \\
\hline \multirow[t]{2}{*}{ Testicular hight } & Assaf & $8.37 \pm 1.13$ & $8.37 \pm 1.15$ & $8.37 \pm 1.13$ & $8.37 \pm 1.1$ \\
\hline & Awassi & $8.65 \pm 0.45$ & $8.65 \pm 0.49$ & $8.65 \pm 0.45$ & $8.65 \pm 0.45$ \\
\hline Testicular volume & Awassi & $667.95 \pm 110.57^{\mathrm{A}}$ & $661.63 \pm 113.6^{A}$ & $666.69 \pm 108.3^{A}$ & $670.39 \pm 109.0^{A}$ \\
\hline \multirow[t]{2}{*}{ Scrotal circumference } & Assaf & $36.37 \pm 0.98^{\mathrm{A}, \mathrm{a}}$ & $34.53 \pm 1.82^{A, b}$ & $34.37 \pm 2.25^{A, b}$ & $36.09 \pm 0.91^{A, a}$ \\
\hline & Awassi & $34.92 \pm 1.58^{\mathrm{B}, \mathrm{a}}$ & $32.92 \pm 1.97^{B, b}$ & $32.65 \pm 1.91^{\mathrm{B}, \mathrm{b}}$ & $34.89 \pm 1.76^{\mathrm{B}, \mathrm{a}}$ \\
\hline \multirow[t]{2}{*}{ Scrotal thickness } & Assaf & $0.32 \pm 0.02^{A}$ & $0.32 \pm 0.02^{A}$ & $0.32 \pm 0.02^{A}$ & $0.32 \pm 0.02^{A}$ \\
\hline & Awassi & $0.27 \pm 0.04^{B}$ & $0.27 \pm 0.04^{B}$ & $0.27 \pm 0.04^{B}$ & $0.27 \pm 0.04^{B}$ \\
\hline
\end{tabular}

Means \pm standard error carrying different capital letters (A, B) within the same column and parameter are significantly differed ( $p \leq 0.05)$ (Effect of breed). Means \pm standard error carrying different superscript ( $a, b, c$, and $d$ ) within the same row and parameter significantly differed ( $p \leq 0.05)$ (Effect of season). 
Table 3. The scrotal circumference and thickness as well as the left testicular length were significantly higher in Assaf breed than Awassi breed. While, left testicular width and volume were significantly higher in Awassi breed than Assaf breed. About season effect, no effect for season was detected except in scrotal circumference which was higher in spring and summer than in autumn and winter season in both breeds.

Effects of season and breed of sheep on semen quality parameters are presented in Table 4 . The volume of semen was significantly higher $(p \leq 0.05)$ in autumn followed by winter then summer and spring in Asaaf breed. The volume of semen was significantly higher $(p \leq 0.05)$ in autumn followed by summer than spring in Awaasi breed. The SCC of semen was significantly higher ( $p \leq$ 0.05 ) in autumn followed by in winter followed by in spring than in summer in Asaaf breed. The SCC of semen was significantly higher $(p \leq 0.05)$ in autumn followed by spring and winter than in summer in Awaasi breed. The sperm motility was significantly higher $(p \leq$
0.05) in winter and spring than in summer in Asaaf breed. No significant differences were detected between sperm motility in different season in Awaasi breed. The sperm abnormality was significantly higher $(p \leq 0.05)$ in summer than other seasons in both breeds. While the lowest sperm abnormality was detected in autumn in all breed. The sperm livability was significantly lower $(p \leq 0.05)$ in summer than other seasons Asaaf breed. The livability was significantly lower $(p \leq 0.05)$ in summer than winter and autumn seasons in Awaasi breed.

The effects of season and breed of sheep pregnancy rate, fecundity, litter size and male to female ratio are presented in Table 5. No abortion was recorded. Therefore, the lambing rate was the same of pregnancy rate. Fecundity and prolificacy were significantly higher in Assaf than Awassi breed during autumn season. While, no significant difference was observed during other seasons.

Table 4. Effects of season and breed of sheep on semen quality parameters

\begin{tabular}{|c|c|c|c|c|c|}
\hline Parameter & & Autumn & Winter & Spring & Summer \\
\hline \multirow[t]{2}{*}{ Volume (mL) } & Assaf & $1.51 \pm 0.02^{\mathrm{a}}$ & $1.22 \pm 0.056^{b}$ & $0.99 \pm 0.096^{c}$ & $1.042 \pm 0.033^{b, c}$ \\
\hline & Awassi & $1.45 \pm 0.03^{\mathrm{a}}$ & $1.067 \pm 0.039^{b, c}$ & $0.97 \pm 0.047^{\circ}$ & $1.125 \pm 0.035^{b}$ \\
\hline \multirow[t]{2}{*}{$\operatorname{SCC}\left(\times 10^{6} / \mathrm{mL}\right)$} & Assaf & $3.60 \pm 0.03^{\mathrm{a}}$ & $3.30 \pm 0.042^{A, b}$ & $3.10 \pm 0.046^{c}$ & $2.800 \pm 0.047^{A}$ \\
\hline & Awassi & $3.60 \pm 0.03^{\mathrm{a}}$ & $3.10 \pm 0.065^{B, b}$ & $3.00 \pm 0.047^{b}$ & $2.60 \pm 0.036^{B}$ \\
\hline \multirow[t]{2}{*}{ Motility \% } & Assaf & $63.08 \pm 0.52^{\mathrm{a}, \mathrm{b}}$ & $64.17 \pm 0.96^{a}$ & $64.33 \pm 1.32^{\mathrm{a}}$ & $60.08 \pm 0.98^{b}$ \\
\hline & Awassi & $64.25 \pm 0.68$ & $64.33 \pm 1.45$ & $63.58 \pm 0.39$ & $61.92 \pm 0.64$ \\
\hline \multirow[t]{2}{*}{ Abnormal \% } & Assaf & $8.0 \pm 0.76^{B, c}$ & $10.0 \pm 0.38^{B, c}$ & $12.0 \pm 0.77^{b}$ & $15.0 \pm 0.53^{\mathrm{a}}$ \\
\hline & Awassi & $10.67 \pm 0.93^{A, b}$ & $13.0 \pm 0.65^{A, b}$ & $11.0 \pm 0.47^{b}$ & $16.0 \pm 0.80^{\mathrm{a}}$ \\
\hline \multirow[t]{2}{*}{ Livability \% } & Assaf & $72.83 \pm 0.70^{\mathrm{a}}$ & $72.33 \pm 1.01^{\mathrm{a}}$ & $71.50 \pm 1.15^{\mathrm{a}}$ & $65.83 \pm 0.86^{b}$ \\
\hline & Awassi & $71.83 \pm 0.86^{a}$ & $71.67 \pm 1.17^{\mathrm{a}}$ & $70.92 \pm 0.81^{a, b}$ & $68.17 \pm 0.64^{b}$ \\
\hline
\end{tabular}

Means \pm standard error carrying different capital letters (A, B) within the same column and parameter are significantly differed ( $p \leq 0.05)$ (Effect of breed) Means \pm standard error carrying different superscript (a, b, c, and d) within the same row and parameter significantly differed ( $p \leq 0.05)$ (Effect of season).

Table 5. Effects of season and breed of sheep fertility, litter size and gender ration in two sheep breeds

\begin{tabular}{|c|c|c|c|c|c|}
\hline Parameter & Breed & Autumn & Winter & Spring & Summer \\
\hline Pregnancy rate & Awassi & $71.67(43 / 60)$ & $53.33(16 / 30)$ & $60.00(18 / 30)$ & $46.67(14 / 30)$ \\
\hline & Awassi & $0.78(47 / 60)$ & $0.57(17 / 30)$ & $0.6(18 / 30)$ & $0.47(14 / 30)$ \\
\hline \multirow[t]{2}{*}{ Litter size } & Assaf & $1.72(112 / 65)^{* *}$ & $1.21(17 / 14)$ & $1.13(18 / 16)$ & $1.08(13 / 12)$ \\
\hline & Awassi & $1.09(47 / 43)$ & $1.06(17 / 16)$ & $1.00(18 / 18)$ & $1.00(14 / 14)$ \\
\hline & Awassi & $20: 27$ & $8: 9$ & $8: 10$ & $6: 8$ \\
\hline
\end{tabular}

${ }^{*} p$ value $=0.09$ (Chi square test) between the two breeds.

${ }^{* *} p$ value $=0.00001$ (Chi square test normalized to twin 2 lambs born from 1 ewe) between the two breeds. 


\section{DISCUSSION}

Seasonal variations in semen characteristics were observed. Semen volume, sperm concentration, percentage of live sperm, abnormal sperms and sperm motility varied within breeds with season change. Semen volume and SCC were significantly higher $(p \leq 0.05)$ in autumn in all breeds. Changes in day length influence testicular activity by modifying the release of GnRH and thus the gonadotropins. In seasonal breeders, the volume of the ejaculate is high in the breeding season and decreases in the nonbreeding Season. The present findings agreed with the results that previously reported for seasonal variations in semen volume and sperm concentration of rams and bucks (Zarazaga et al., 2009; Suhair and Abdalla, 2010). In our study, some variations were detected in semen motility among seasons. These findings were in agreement with the results of (Ibrahim, 1997) and (Fowler, 1965) who reported seasonal variations of progressive sperm motility in local crossbred and Merino rams. This response can be caused by different Factors, including availability of essential nutrients in various seasons (Onstad, 1967; Amir and Volcani, 2009) and seasonal variations of hormonal profile (Dorostgoal, 2006; Hamidi et al., 2010). In our study, sperm abnormalities were significantly highest $(p \leq 0.05)$ in summer and lowest in autumn in all breeds. The high summer temperature had also its adverse effect on sperm livability. These results agree with the results of (Gündoğan, 2007) who reported a moderate decrease of abnormal sperms in breeding season (autumn) as Compared to the non-breeding season in Daglic fattailed rams. Galil and Galil (2009) and Suhair and Abdalla (2010) reported seasonal change in percentage of live and abnormal sperms in desert rams. Decreased live sperm percentage and increased abnormal sperm percentage in non-breeding season could be related to the decrease in number of seminiferous tubules and increase in degenerative processes (Suhair and Abdalla, 2010). Our results showed significant seasonal variation in testosterone level in all breeds. These results are in agreement with the results of (Abecia et al., 2012) who recorded that the reproductive seasonality is a phenomenon influenced mainly by annual variations in the photoperiod such that reproductive and non-reproductive seasons are well defined among seasonal species. The current results are also in agreement with the results of (Dorostgoal, 2006; Hamidi et al., 2010) who recorded seasonal variations of hormonal profile in different breeds of sheep among different seasons. Nonetheless, the magnitude of these seasonal effects should not prevent the animals from breeding.

In conclusion, the results showed the superiority of Assaf over Awassi breed in the given seasonal conditions and offer a good model of breeding with increased twinning rates specially in autumn season.

\section{CONFLICTS OF INTEREST}

No potential conflict of interest relevant to this article was reported.

\section{AUTHOR CONTRIBUTIONS}

HA Zaher: Conceptualization, Methodology, Visualization, Supervision.

SA Alawaash: Project administration, Funding acquisition, Supervision, Resources.

AA Swelum: Methodology, Data analysis, Visualization, Writing - review \& editing.

\section{AUTHOR'S POSITION AND ORCID NO.}

HA Zaher, Associate Professor, https://orcid.org/0000-0003-1834-2589

SA Alawaash, Master Degree, https://orcid.org/0000-0001-8368-5903

AA Swelum, Associate Professor, https://orcid.org/0000-0003-3247-5898

\section{REFERENCES}

Abecia JA, Forcada F, González-Bulnes A. 2012. Hormonal control of reproduction in small ruminants. Anim. Reprod. Sci. 130:173-179.

Al Samarrae SH. 2009. Semen quality of Arrabi and Karradi Iraqi rams. Diyal. Agric. Sci. J. 1:30-36.

Amir D and Volcani R. 1965. Seasonal fluctuations in the sexual activity of Awassi, German Mutton Merino, Corriedale, Border-Leicester and Dorset Horn rams: I. Seasonal changes in semen plasma volume and its fructose and citric acid concentrations. J. Agric. Sci. 64:115-120.

Dorostgoal M. 2006. Histological and morphometrical studies of seminiferous tubules and leydig cells of Khouzestan Arabian rams in different seasons of a year by light and electron microscope. University of Shahid Chamran, Ahwaz, Iran, pp. 
74-122.

FAO. 1991. Asian livestock. Monthly technical magazine of the FAO. Animal Production and Health Commission for Asia and the Pacific (APHCA). 8:85-87.

Fowler DG. 1965. Semen quality of Merino rams. 1. The effects of fleece length and season on semen quality. Aust. J. Exp. Agric. 5:243-246.

Galil KAA and Galil AKA. 1982. Seasonal variation in some characteristics of seminal plasma of Sudan Desert sheep in the tropics. J. Agric. Sci. 99:45-49.

Gündoğan M. 2007. Seasonal variation in serum testosterone, T3 and andrological parameters of two Turkish sheep breeds. Small Rumin. Res. 67:312-316.

Hamidi A, Mamouei M, Mirzadeh K, Tabatabaei S, Roshanfekr H. 2010. Seasonal changes of blood testosterone concentration and its association with reproductive parameters in Arabian breed ram. Proc 4th Iranian Cong Anim Sci, Tehran, September 20-21, pp. 426.

Ibrahim SA. 1997. Seasonal variations in semen quality of local and crossbred rams raised in the United Arab Emirates. Anim. Reprod. Sci. 49:161-167.

Karagiannidis A, Varsakeli S, Karatzas G. 2000. Characteristics and seasonal variations in the semen of Alpine, Saanen and Damascus goat bucks born and raised in Greece. Theriogenology 53:1285-1293.

Kunavongkrit A, Suriyasomboon A, Lundeheim N, Heard TW, Einarsson S. 2005. Management and sperm production of boars under differing environmental conditions. Theriogenology 63:657-667.

Land RB and Carr WR. 1975. Testis growth and plasma LH concentration following hemicastration and its relation with female prolificacy in sheep. J. Reprod. Fertil. 45:495-501.

Malejane CM, Greyling JPC, Raito MB. 2014. Seasonal variation in semen quality of Dorper rams using different collection techniques. South Afr. J Anim. Sci. 44:26.

Moghaddam GH, Pourseif MM, Rafat SA. 2012. Seasonal variation in semen quantity and quality traits of Iranian crossbred rams. Slovak J. Anim. Sci. 45:67-75.

Onstad O. 1967. Studies on postnatal testicular changes, semen quality, and anomalies of reproductive organs in the mink. Acta Endocrinol. 55(3_Suppl):S9-SNP.

Suhair SM and Abdalla MA. 2010. Effects of level of feeding and season on thermoregulation and semen characteristics in
Desert rams (Ovis aries). Glob. Vet. 4:207-215.

Swelum AA, Alowaimer AN, Abouheif MA. 2014. Effects of breed and number of embryos transferred on the efficacy of MOET in sheep. J. Anim. Vet. Adv. 13:98-103.

Swelum AA, Alowaimer AN, Abouheif MA. 2015. Use of fluorogestone acetate sponges or controlled internal drug release for estrus synchronization in ewes: Effects of hormonal profiles and reproductive performance. Theriogenology 84:498503.

Swelum AA, Ayadi M, Alhidary I, Alowaimer A, Abouheif M. 2017. The relationships between body fatness, leptin, testosterone, and reproductive performance in ram lambs as affected by level and frequency of feeding. Theriogenology 89:79-85.

Swelum AA, Saadeldin IM, Moumen AF, Ali MA, Alowaimer AN. 2018a. Efficacy of controlled internal drug release (CIDR) treatment durations on the reproductive performance, hormone profiles, and economic profit of Awassi ewes. Small Rumin. Res. 166:47-52.

Swelum AA, Saadeldin IM, Moumen AF, Ali MA, Ba-Awadh H, Alowaimer AN. 2018b. Efficacy of using previously used controlled internal drug release (CIDR) insert on the reproductive performance, hormone profiles and economic measures of sheep. Reprod. Domest. Anim. 53:1114-1122.

Talebi J, Souri M, Moghaddam A, Karimi I, Mirmahmoodi M. 2009. Characteristics and seasonal variation in the semen of Markhoz bucks in western Iran. Small Rumin. Res. 85:18-22.

Todini L, Malfatti A, Terzano GM, Borghese A, Pizzillo M, Debenedetti A. 2007. Seasonality of plasma testosterone in males of four Mediterranean goat breeds and in three different climatic conditions. Theriogenology 67:627-631.

Yu YJ, Park SH, Shin SM, Yang BC, Seong PN, Woo JH, Kim NY, Son JK. 2017. Effect of ovarian changes according to four season for reproduction of Jeju crossbred horses. J. Emb. Trans. 32:177-182.

Zarazaga LA, Guzmán JL, Domínguez C, Pérez MC, Prieto R. 2009. Effects of season and feeding level on reproductive activity and semen quality in Payoya buck goats. Theriogenology 71:1316-1325.

Zarei MA, Farshad A, Akhondzadeh S. 2009. Variations in thyroidal activity during estrous cycle and natural breeding season in Markhoz goat breeds. Pak. J. Biol. Sci. 12:14201424 . 